\title{
An Observational Study of Sun-Protective Behaviour at an Outdoor Spectator Sporting Event in a Region of High Sun Exposure
}

Jane Nikles* and Simone Lee Harrison

Skin Cancer Research Group, The Anton Breinl Centre, School of Public Health, Tropical Medicine and Rehabilitation Sciences, James Cook University, Queensland, Australia

*Corresponding author: Dr Jane Nikles, Senior Research Fellow, Skin Cancer Research Group, School of Public Health and Tropical Medicine, James Cook University of North Queensland James Cook Dr Townsville Qld 4811, Townsville, Queensland, Australia, Tel: +61 73374 3898; E-mail: uqjnikle@uq.edu.au

Recieved date: Mar 18, 2014, Accepted date: Apr 21, 2014, Published date: Apr 27, 2013

Copyright: ( 2014 Nikles J, et al. This is an open-access article distributed under the terms of the Creative Commons Attribution License, which permits unrestricted use, distribution, and reproduction in any medium, provided the original author and source are credited

\begin{abstract}
Introduction: Few studies have described observed sun-protection behaviours. We aimed to describe the prevalence of observed sun-protection behaviour of a high-risk population in tropical Queensland engaged in outdoor leisure activity, to act as a baseline for future comparisons and to highlight the need for further work to improve sun-protective behaviours in this high risk population.
\end{abstract}

Methods: Unobtrusive observations of clothing worn by 457 attendees at the Supercar Championship in Townsville, Queensland, Australia were conducted in an unshaded area around solar noon, in July 2009. A descriptive and chi-square analysis was conducted using SPSS.

Results: Caps were the most popular hat choice. Significantly more children $(45.1 \%)$ than adults $(27.1 \%)$ wore wide-brimmed/legionnaires/ bucket hats. Many women (35.3\%), girls (26.3\%), men (24.5\%) and boys (18.8\%) wore no hat. Significantly more females $(34.3 \%)$ than males $(23.9 \%)$ wore no hat.

Significantly more women (17.4\%) than men (6.6\%) wore full-length/3/4-sleeves. Short-sleeve shirts were worn by $90 \%$ of men and $55 \%$ of women. A further $28 \%$ of women wore sleeveless/cap-sleeved shirts. These proportions were significantly different.

More girls $(27.7 \%)$ than boys (3\%) wore sleeveless/cap-sleeved shirts. More boys $(87.9 \%)$ than girls $(61.1 \%)$ wore short-sleeves. Both these proportions were significantly different. Full-length/ $3 / 4$-sleeves were equally uncommon among boys $(9.1 \%)$ and girls $(11.1 \%)$.

Conclusions: Despite a widespread SunSmart campaign in Australia over the past three decades, observed sun protection behaviour at this event were not consistent with Cancer Council Australia recommendations for personal sun protection.

Keywords: Skin cancer; Australia; Ultraviolet radiation; Sun protection; Spectator sport

\section{Introduction}

Non-melanocytic skin cancer is the most frequently diagnosed malignancy in Australia [1], with 80 per cent of all cancers diagnosed in Australia being skin cancer. Each year, more than 430,000 Australians are treated for skin cancers [2]; 767,347 treatments for non-melanoma skin cancers (NMSC) are carried out [2], over 10,500 new cases of melanoma are diagnosed, and there are around 2087 deaths from melanoma and non-melanoma skin cancer [3]. At an estimated \$511 million per year in 2010, skin cancer costs the Australian health system much more than any other form of cancer [2]. The burden is greatest in Queensland [4], where the incidence of melanoma is also extremely high $(83.4 / 100,000$ in males, $53.8 / 100,000$ in females [5] in 2010). The corresponding figures for Australia overall are 62.7/100,000 in males and 39.9/100,000 in females [5].

The National Sun Smart Program was developed by the Cancer Council of Victoria more than two decades ago. This very successful cancer control program [6] has been adopted in several other countries from Hawaii [7] to South Africa [8] although its effectiveness in Australia appears to have declined recently $[9,10]$.

Thousands of Queenslanders (both adults and children) are involved in outdoor sports, often during peak ultraviolet radiation (UVR) periods (between 10 am and $3 \mathrm{pm}$ ), which carries the risk of increased exposure to UVR and therefore risk of developing skin cancer [11]. Children are especially vulnerable to the effects of UVR [12]. Children raised in Queensland develop pigmented moles (the most important phenotypic risk factor for melanoma) earlier and more frequently than children raised elsewhere $[13,14]$.

Relatively few observational studies of sun protective behaviours have been conducted. Most population-based surveys have relied on self-reported sun-protection behaviour, which can be subject to recall and misclassification bias and social desirability bias [15]. Indications of recall bias for melanoma risk factors have been observed, though small and inconsistent [16]. Anecdotal evidence shows that hats and sun-protective clothing are not widely used in Queensland. This study describes the prevalence of child and adult spectators 
Citation: Nikles J and Harrison SL (2014) An Observational Study of Sun-Protective Behaviour at an Outdoor Spectator Sporting Event in a Region of High Sun Exposure . J Carcinog Mutagen S4: 003. doi:10.4172/2157-2518.S4-003

Page 2 of 6

observed sun protection behaviour (hat type, sleeve length and shade use) at a motorsport event in Townsville, Queensland. The hypothesis was that hat and sun-protective clothing use by spectators at a typical outdoor spectator sporting event in tropical Queensland would be poor.

\section{Materials and Methods}

The inaugural V8 Supercar Championship in Townsville (latitude $19.25^{\circ} \mathrm{S}$, longitude $146.77^{\circ} \mathrm{E}$ ) was chosen as an example of a Queensland outdoor leisure activity. The Townsville Street Circuit was attended by 167,057 spectators over three days [17] and had five viewing mounds and unshaded grandstands capable of seating 12,000 spectators. Shade was limited, for both race visibility and logistic reasons.

An observer (SLH) experienced in conducting field observations of sun protective behaviours (refer Turner 2014 [18]) conducted unobtrusive observations of attendees' hat style and sleeve length, from a position close to the spectator entrance to the motor precinct. Spectators were observed walking through the entry gate to minimize double counting individuals. Age (adult/child according to tickets: child 0-12 years), gender, hat type (6 categories: wide-brim/ legionnaires/bucket hat/cap/visor/ none), sleeve length (5 categories: long-sleeves/3/4-sleeves/ short-sleeves/cap-sleeves/sleeveless) and race (Caucasian/Dark-Skinned) were recorded.

Consecutive paper-based observations were conducted of all children and adults walking through the unshaded entry gate between

\begin{tabular}{|c|c|c|c|c|c|c|c|c|c|c|c|c|c|}
\hline HAT TYPEa & \multicolumn{2}{|l|}{$\mathrm{N}(\%)$} & \multicolumn{2}{|c|}{ Adults $\mathrm{N}=403^{\mathrm{a}}(\%)$} & \multicolumn{3}{|c|}{ Children $\mathrm{N}=51^{\mathrm{a}}(\%)$} & $\mathrm{P}$ Value & \multicolumn{2}{|c|}{ Male $\mathrm{N}=285 \mathrm{a}(\%)$} & \multicolumn{2}{|c|}{$\begin{array}{l}\text { Female } \\
\mathrm{N}=169^{\mathrm{a}}(\%)\end{array}$} & $\mathrm{P}$ Value \\
\hline No Hat ${ }^{b}$ & $126(27$. & \multirow{3}{*}{$\begin{array}{l}322(70.9) \\
\mathrm{b}\end{array}$} & \multicolumn{2}{|l|}{$115(28.5)$} & \multirow{3}{*}{$\begin{array}{l}294(72 . \\
9)\end{array}$} & $11(21$. & \multirow{3}{*}{$\begin{array}{l}28(54 . \\
9)\end{array}$} & \multirow{6}{*}{$\begin{array}{l}F E<0.0005 d x \\
20.007 d x^{2} 0.295\end{array}$} & $68(23.9)$ & \multirow{3}{*}{$\begin{array}{l}202(70 . \\
9)\end{array}$} & $58(34$. & \multirow{3}{*}{$\begin{array}{l}120(71 . \\
0)\end{array}$} & \multirow{6}{*}{$\begin{array}{l}\text { FE } 0.056 x^{2} \\
0.977 x^{2} \\
0.016^{d} .\end{array}$} \\
\hline Visor $^{b}$ & $6(1.3)$ & & $6(15)$ & 0 & & $2(07)$ & & & $4(24)$ & & & & \\
\hline Cap ${ }^{b}$ & $\begin{array}{l}190(41 . \\
9)\end{array}$ & & $\begin{array}{l}173(42 . \\
9)\end{array}$ & $13(25.5)$ & & $\begin{array}{l}132(46 \\
.3)\end{array}$ & & & $58(34.4)$ & & & & \\
\hline Bucket $^{c}$ & $50(11)$ & \multirow[t]{3}{*}{$\begin{array}{l}132(29.1) \\
c\end{array}$} & \multicolumn{2}{|l|}{$37(9.2)$} & \multirow[t]{3}{*}{$\begin{array}{l}109(27 . \\
1)\end{array}$} & $\begin{array}{l}13(25 . \\
5)\end{array}$ & \multirow[t]{3}{*}{$\begin{array}{l}23(45 . \\
1)\end{array}$} & & $32(11.2)$ & \multirow[t]{3}{*}{$83(29.1)$} & $\begin{array}{l}18(10 . \\
7)\end{array}$ & \multirow[t]{3}{*}{$49(29.0)$} & \\
\hline Legionnaires $^{c}$ & $3(0.7)$ & & 0 & $3(5.9)$ & & $2(0.7)$ & & & $1(0.6)$ & & & & \\
\hline $\begin{array}{l}\text { Wide- } \\
\text { brimmed hat }{ }^{\mathrm{C}}\end{array}$ & $79(17.0)$ & & $72(17.9)$ & $7(13.7)$ & & $\begin{array}{l}49(17 . \\
2)\end{array}$ & & & $30(17.8)$ & & & & \\
\hline $\begin{array}{l}\text { SLEEVE } \\
\text { LENGTH }\end{array}$ & \multicolumn{2}{|l|}{$\mathrm{N}(\%)$} & \multicolumn{2}{|c|}{ Adults (\%) } & \multicolumn{3}{|c|}{ Children $\mathrm{N}=51^{\mathrm{a}}(\%)$} & $\mathrm{P}$ Value & \multicolumn{2}{|l|}{ Male $(\%)$} & \multicolumn{2}{|l|}{ Female } & $\mathrm{P}$ Value \\
\hline $\begin{array}{l}\text { Sleeveless } \\
\text { tope }\end{array}$ & $51(11.3)$ & \multirow[t]{3}{*}{$\begin{array}{l}404(89.4 \\
) e\end{array}$} & $46(11.5)$ & $\begin{array}{l}358(89 . \\
3)\end{array}$ & $5(9.8)$ & \multirow{3}{*}{\multicolumn{2}{|c|}{$46(90.2$}} & FE $0.864 \chi^{2} 0.841$ & $9(3.2)$ & \multirow[t]{3}{*}{$\begin{array}{l}264(93 . \\
0)\end{array}$} & $\begin{array}{l}42(25 . \\
0)\end{array}$ & \multirow[t]{3}{*}{$\begin{array}{l}140(83 . \\
3)\end{array}$} & \multirow[t]{4}{*}{$\begin{array}{l}x^{2<0.0005 d} \\
x^{2} 0.001 d\end{array}$} \\
\hline Cap sleeves ${ }^{\mathrm{e}}$ & $5(1.1)$ & & $4(1.0)$ & & $1(2.0)$ & & & & 0 & & $5(3.0)$ & & \\
\hline $\begin{array}{l}\text { Short } \\
\text { sleeves }^{\mathrm{e}}\end{array}$ & $348(77)$ & & $\begin{array}{l}308(76 . \\
8)\end{array}$ & & $40(78.4)$ & & & & $\begin{array}{l}255(89 . \\
8)\end{array}$ & & $\begin{array}{l}93(55 . \\
4)\end{array}$ & & \\
\hline $3 / 4$ sleeves $^{f}$ & $15(3.3)$ & $48(10.6) f$ & $14(3.5)$ & $43(10.7)$ & $1(2.0)$ & $5(9.8)$ & & & $5(1.8)$ & $20(7.0)$ & $10(6.0)$ & $28(16.7)$ & \\
\hline
\end{tabular}

$11 \mathrm{am}$ and $12.30 \mathrm{pm}$ on Sunday 12th July 2009. Peak UVR levels are recorded between $11 \mathrm{am}$ and $3 \mathrm{pm}$. The weather on this clear-sky, mid-winter day was fine and warm (average temperature $18^{\circ} \mathrm{C}$, average humidity $71 \%$ ) with a maximum daily UV-index of 7 during the observation period. Wind speed was $10-28 \mathrm{~km} / \mathrm{hr}$ [19].

\section{Statistical analyses}

Data was entered into SPSS, version 20 and analysed using descriptive and chi-square statistics. The cut-off for significance was set at $\mathrm{p}=0.05$.

\section{Results}

$405(88.6 \%)$ adults and $52(11.4 \%)$ children were observed, most of whom $(99.1 \%)$ were Caucasian and male $(62.8 \%)$.

$27.8 \%$ of people observed were not wearing a hat (Table 1). The most commonly worn headwear was caps $(41.9 \%)$, followed by widebrimmed hats $(17.0 \%)$, bucket hats $(11.0 \%)$, visors $(1.3 \%)$, and legionnaire hats $(0.7 \%)$.

Overall, 35.3\% of women did not wear a hat followed by girls (26.3\%), men (24.5\%) and boys (18.8\%; Table 2). Similar proportions of men and women $(\mathrm{p}=0.730)$ and boys and girls $(\mathrm{p}=0.561)$ wore sunprotective hats, although women were more likely than men to wear no hat $(\mathrm{p}=0.023)$. 
Citation: Nikles J and Harrison SL (2014) An Observational Study of Sun-Protective Behaviour at an Outdoor Spectator Sporting Event in a Region of High Sun Exposure. J Carcinog Mutagen S4: 003. doi:10.4172/2157-2518.S4-003

Page 3 of 6

\begin{tabular}{|l|l|l|l|l|l|l|l|l|l|l|l|l|}
\hline $\begin{array}{l}\text { Long } \\
\text { sleevesf51(11 } \\
\text { 3) }\end{array}$ & $33(7.3)$ & & 29(7.2) & & $4(7.8)$ & & & $15(5.3)$ & & $\begin{array}{l}18(10 . \\
7)\end{array}$ & & \\
\hline
\end{tabular}

Table 1: Hat type and sleeve length of spectators at V8 Supercar Championship Townsville 2009, by age and gender. a HAT TYPE is missing for 3 subjects ( 1 man, 1 woman \& 1 boy); ${ }^{b}$ Non-SunSmart headwear [i.e no hat/cap/visor]; ${ }^{c}$ SunSmart recommended hat styles [i.e. wide-brimmed/ legionnaires/bucket hat];Upper p-value compares 6 categories of hat styles (no hat/visor/cap/bucket/wide-brimmed); Middle p-value compares 2 categories of hat styles (Non-SunSmart headwear including no hat vs SunSmart hats); Lower p-value compares no hat vs hat of any kind; dstatistically-significant result (i.e. p $<0.05$ ); FE Fisher's Exact Test; 22 Pearson's Chi-squared Test; SLEEVE-LENGTH is missing for 5 subjects (Four adults \& one child); ${ }^{e}$ Non-SunSmart sleeve types [i.e sleeveless/cap-sleeve/short-sleeve]; fSunSmart recommended sleeve-styles [3/4 and full length sleeves]; Upper p-value compares 5 sleeve lengths (sleeveless/cap-sleeves/short-sleeves/3/4 sleeves/long sleeves); Lower p-value compares Non-SunSmart vs SunSmart recommended sleeve-lengths.

\begin{tabular}{|c|c|c|c|c|c|c|c|c|c|c|c|c|c|}
\hline HAT & \multicolumn{2}{|l|}{$\mathrm{N}(\%)$} & \multicolumn{2}{|l|}{ Men (\%) } & \multicolumn{3}{|c|}{ Women (\%) } & \multirow{2}{*}{\begin{tabular}{l|l} 
PValue \\
$\begin{array}{l}\text { FE } 0.055 x^{2} 0.730 x^{2} \\
0.023 c\end{array}$
\end{tabular}} & \multicolumn{2}{|c|}{ Women (\%) } & \multicolumn{2}{|c|}{ Girls (\%) } & \multirow{2}{*}{$\begin{array}{l}\text { PValue } \\
\text { FE0.674 } x^{2} \\
0.561 \text { FE } 0.726\end{array}$} \\
\hline $\begin{array}{l}\text { HAT } \\
\text { TYPE }\end{array}$ & $\begin{array}{l}126(27 . \\
8)\end{array}$ & \multirow[t]{3}{*}{$\begin{array}{l}322(70.9 \\
)^{a}\end{array}$} & \multicolumn{2}{|l|}{$62(24.5)$} & \multirow[t]{3}{*}{$\begin{array}{l}\text { 183(72. } \\
3)\end{array}$} & $\begin{array}{l}53(35 \\
3)\end{array}$ & \multirow[t]{3}{*}{$\begin{array}{l}111(74 . \\
0)\end{array}$} & & $6(18.8)$ & \multirow[t]{3}{*}{$\begin{array}{l}19(59 . \\
4)\end{array}$} & $5(26.3)$ & \multirow[t]{3}{*}{$9(47.4)$} & \\
\hline Visor $^{\mathrm{a}}$ & $6(1.3)$ & & $2(0.8)$ & $4(2.7)$ & & $0(0.0)$ & & & $0(0.0)$ & & & & \\
\hline Capa & $\begin{array}{l}190(41 . \\
9)\end{array}$ & & $\begin{array}{l}119(47 . \\
0)\end{array}$ & $54(36.0)$ & & $\begin{array}{l}13(40 \\
6)\end{array}$ & & & $4(21.1)$ & & & & \\
\hline Bucket $^{\mathrm{b}}$ & $50(11)$ & & \multicolumn{2}{|l|}{$25(9.9)$} & \multirow[t]{3}{*}{$70(27.7)$} & $12(8.0)$ & \multirow[t]{3}{*}{$39(26.0)$} & & $7(21.9)$ & \multirow{3}{*}{$\begin{array}{l}13(40 . \\
6)\end{array}$} & $6(31.6)$ & \multirow{3}{*}{$\begin{array}{l}10(52 . \\
6)\end{array}$} & \\
\hline $\begin{array}{l}\text { Legion- } \\
\text { naires }^{b}\end{array}$ & $3(0.7)$ & & $0(0.0)$ & $0(0.0)$ & & $2(6.2)$ & & & $1(5.3)$ & & & & \\
\hline $\begin{array}{l}\text { Wide- } \\
\text { brimmed } \\
\text { hat }^{\mathrm{b}}\end{array}$ & $79(17.0)$ & & $45(17.8)$ & $27(18.0)$ & & $4(12.5)$ & & & $3(15.8)$ & & & & \\
\hline $\begin{array}{l}\text { SLEEVE } \\
\text { LENGT } \\
\mathrm{H}\end{array}$ & \multicolumn{2}{|l|}{$N(\%)$} & \multicolumn{2}{|l|}{ Men (\%) } & \multicolumn{3}{|c|}{ Women (\%) } & $P$ Value & \multicolumn{2}{|c|}{ Boys (\%) } & \multicolumn{2}{|l|}{ Girls (\%) } & $P$ Value \\
\hline $\begin{array}{l}\text { Sleevele } \\
\text { ss top }\end{array}$ & $51(11.3)$ & \multirow[t]{3}{*}{$\begin{array}{l}404(89.4 \\
)^{d}\end{array}$} & $8(3.2)$ & $\begin{array}{l}\text { 234(93. } \\
\text { 2) }\end{array}$ & $38(25.3)$ & \multirow{3}{*}{\multicolumn{2}{|c|}{$124(82.7)$}} & \multirow[t]{5}{*}{$\begin{array}{l}\mathrm{FE} \\
<0.0005 c x^{2} 0.001^{c}\end{array}$} & $1(3.0)$ & \multirow[t]{3}{*}{$\begin{array}{l}30(90 . \\
9)\end{array}$} & $4(22.2)$ & \multirow[t]{3}{*}{\begin{tabular}{|l}
16 \\
$(88.9)$
\end{tabular}} & \multirow[t]{5}{*}{ FE 0.037 c FE 1.00} \\
\hline $\begin{array}{l}\text { Cap } \\
\text { sleeves }^{\text {d }}\end{array}$ & $5(1.1)$ & & $0(0.0)$ & & $4(2.7)$ & & & & $0(0.0)$ & & $1(5.5)$ & & \\
\hline $\begin{array}{l}\text { Short } \\
\text { sleeves }\end{array}$ & $348(77)$ & & $\begin{array}{l}226(90 . \\
0)\end{array}$ & & $82(54.7)$ & & & & $\begin{array}{l}29(87 . \\
9)\end{array}$ & & $\begin{array}{l}\text { 11(61. } \\
\text { 1) }\end{array}$ & & \\
\hline $\begin{array}{l}3 / 4 \\
\text { sleeves }^{\mathrm{e}}\end{array}$ & $15(3.3)$ & $\begin{array}{l}404(89.4 \\
) d\end{array}$ & $4(1.6)$ & $17(6.8)$ & $10(6.7)$ & \multirow{2}{*}{\multicolumn{2}{|c|}{$26(17.4)$}} & & $1(3.0)$ & \multirow[t]{2}{*}{$3(9.1)$} & $0(0.0)$ & \multirow[t]{2}{*}{ 2(11.1) } & \\
\hline $\begin{array}{l}\text { Long } \\
\text { sleevese }\end{array}$ & $33(7.3)$ & & $13(5.2)$ & & $16(10.7$ & & & & $2(6.1)$ & & $2(11.1)$ & & \\
\hline
\end{tabular}

Table 2: Hat type and sleeve length of spectators at V8 Supercar Championship Townsville 2009, by men/women and boys/girls. HAT TYPE is missing for 3 subjects (Two adults \& one child); a Non-SunSmart headwear [i.e no hat/cap/visor]; bSunSmart recommended hat styles [i.e. widebrimmed/legionnaires/bucket hat]; Upper p-value compares 6 categories of hat styles (no hat/visor/cap/bucket/wide-brimmed); Middle p-value compares 2 categories of hat styles (Non-SunSmart headwear including no hat vs SunSmart hats); Lower p-value compares no hat vs hat of any kind; cstatistically-significant result (i.e. p $<0.05$ ); FE Fisher's Exact Test; $\chi 2$ Pearson's Chi-squared Test; SLEEVE-LENGTH is missing for 5 subjects (Four adults \& one child); d Non-SunSmart sleeve types [i.e sleeveless/cap-sleeve/short-sleeve];eSunSmart recommended sleeve-styles[3/4 and full length sleeves]; Upper p-value compares 5 sleeve lengths (sleeveless/cap-sleeves/short-sleeves/3/4 sleeves/long sleeves); Lower p-value compares Non-SunSmart vs SunSmart recommended sleeve-lengths.

The proportions of adults and children wearing a hat of any kind were not significantly different $207(71.5 \%)$ vs. $40(78.4 \%)$; $\mathrm{p}=0.25$. Although more children (45.1\%) than adults (27.1\%) wore sunprotective headwear $(\mathrm{p}=0.007)$, the proportions of adults $(71.5 \%)$ and children $(78.4 \%)$ wearing hats of any kind were similar $(\mathrm{p}=0.295)$ and baseball caps were the most popular choice for both age groups (Table $1)$. More children wore bucket/legionnaires hats than adults (31.4\% vs.
9.2\%), while adults (44.4\%) wore caps/visors more often than children $(33.3 \% ; \mathrm{p}<0.001)$. Aside from females $(34.3 \%)$ being more likely than males $(23.9 \%)$ to wear no hat $(\mathrm{p}=0.016)$, there were no obvious gender differences in preferred hat styles $(\mathrm{p}=0.056)$ or tendency towards wearing sun-protective hats $(\mathrm{p}=0.977)$. Notably, $70.9 \%$ of males and $71.0 \%$ of females were not wearing sun-protective hats. 
Most people observed wore short sleeves (77.0\%), followed by a sleeveless top exposing the arms, shoulders and décolletage region (11.3\%), full-length or $3 / 4$-sleeves $(10.6 \%)$, or cap-sleeves $(1.1 \%)$ covering only the shoulder region. Thus, $89.4 \%$ of people observed wore a garment that exposed most or all of the skin on their arms (Table 1). Very few children $(9.8 \%)$ wore long or $3 / 4$ sleeves, while $78.4 \%$ wore short sleeves and $11.8 \%$ wore a sleeveless shirt or cap sleeves. The proportions were very similar for adults (Table 1), consequently no significant differences were found between age groups when comparing sleeve-styles $(\mathrm{p}=0.864)$ or the proportion wearing a sun-protective shirt $(\mathrm{p}=0.841)$.

However, females were more likely than males to wear a sleeveless shirt or cap sleeves $(28.0 \%$ vs. $3.2 \%$; $\mathrm{p}<0.0005)$; males were more likely than females to wear short sleeves ( $89.8 \%$ vs. $55.4 \%)$, and females were more likely than males to wear sun-protective sleeves ( $16.7 \%$ vs. $7.0 \%$; $\mathrm{p}=0.001$ ). Notably, $93.0 \%$ of males and $83.3 \%$ of females were not wearing sun-protective sleeves.

The vast majority (90.0\%) of men and just over half the women wore short sleeves and a further $28.0 \%$ of women wore a sleeveless shirt or cap sleeves $(\mathrm{p}<0.001)$. A higher proportion of women than men wore full-length or $3 / 4$-sleeves $(\mathrm{p}=0.001)$. This pattern was mirrored for boys and girls, with $27.7 \%$ of girls and only $3.0 \%$ of boys wearing a sleeveless shirt or cap-sleeves and $87.9 \%$ of boys and $61.1 \%$ of girls wearing short sleeves ( $\mathrm{p}=0.037$ ), except that overall, boys and girls were similar with respect to the proportion wearing sunprotective sleeves $(\mathrm{p}=1)$.

\section{Discussion}

\section{Reducing skin cancer risk}

UVR plays a pivotal role in the development of both melanoma and non-melanoma skin cancers, causing at least $95 \%$ of these cancers [11]. Sixty-six per cent of Australians will be diagnosed with skin cancer before the age of 70 [20]. Various prevention strategies ameliorate this risk, including avoiding sun exposure during peak UVR times, applying sunscreen with a sun protection factor of 30 or above before participating in outdoor activities, wearing hats, sunglasses and garments which cover much of the skin [21,22].

To protect skin and eyes from UVR, the Cancer Council Australia recommends hats that protect the face, back of the neck, eyes and ears. Broad-brimmed, bucket or legionnaire hats offer the best protection from UV radiation, providing the brim is wide enough (greater than $7.5 \mathrm{~cm}$ ) [23]. Baseball or peaked caps and sun visors are not recommended as although they offer good protection to the nose they are relatively ineffective at protecting other facial sites such as the ears and posterior neck [24]. Hats alone are not an adequate form of sun protection. Polysulfone dosimeters were used to measure the erythemally effective UV exposure to facial sites of 45 unprotected high school students (no hat) and protected students (hat), in Hervey Bay, Australia (latitude $25.3^{\circ} \mathrm{S}$ ). All hourly facial exposures exceeded the National Health and Medical Research Council's adopted safe daily limit of $30 \mathrm{~J} \mathrm{~m} \mathrm{(-2),} \mathrm{even} \mathrm{for} \mathrm{those} \mathrm{wearing} \mathrm{hats} \mathrm{[25].}$

Recent research indicates that the likelihood of multiple sunburns is significantly lower in individuals who frequently wear long-sleeves $(\mathrm{OR}=0.73, \mathrm{p}=0.01)[26]$ and that wearing clothing which covers a high proportion of the skin surface during childhood can slow the rate of development of pigmented moles in children [27]. Certain fabrics such as synthetic fabrics have Ultraviolet Protection Factor values over 500, making them vastly superior to sunscreen [28]. Though sleeve length was only used for sun-protection by a relatively small percentage of those observed in this study, an observational study of 46,810 teenagers and adults at outdoor leisure activities near Melbourne, Australia, found significant improvements in the extent of body clothes cover over the decade 1992 to 2002 [29]. Sunglasses are necessary to protect the eyes from UVR, and are also underutilised in Australia. The same observational field survey found that only $36.2 \%$ of teenagers and adults observed wore sunglasses [30].

\section{Other observational studies of sun protective behaviour}

Other studies of spectators at outdoor sporting events are few. Observational studies in 2001 showed that 70 per cent of Australian tennis fans wore a hat while watching centre court tennis action [31]. Despite the intense levels of UVR that Americans attending a daytime baseball game are typically exposed to, only $45 \%$ of those seated in sunny locations wore hats. Even knowing in advance that seating would be in the sun or being in continuous sun for 2 hours did not increase head covering [32]. This study was conducted in the US, where there are different demographics, social norms and history of skin cancer prevention programs to those in Australia.

\section{Queenslanders' self-reported sun protective behaviour}

Although the risk is documented and well known, people continue to overexpose themselves and their children to UVR. A recent survey of Queenslanders [33] found that sun exposure levels were high, with more than half of the Queensland adult population getting sunburnt in the previous year, including 75\% of 16-17 year old Queenslanders. Only 2.5 percent of adult Queenslanders practice all five recommended sun protective behaviors, "Slip, Slop, Slap, Seek and Slide" during winter, and 5.9\% in summer.

\section{Barriers to skin cancer prevention behaviours}

Barriers to skin cancer prevention behaviours include lack of availability of sunscreen, lack of information about sun safety behaviours, uncertainty about effectiveness of sun protection strategies, social reasons, dress code, first sunny day since weeks, wind squalls, inconvenience, Fashion concerns, desire for a tan, weather context, misconceptions about vitamin $\mathrm{D}$ requirements, and lack of adequate time to reapply sunscreen during open field activity $[34,35]$.

\section{Recommendations}

The authors recommend that better shade provision become a priority at outdoor recreational venues. In addition, the authors recommend offering shade umbrellas (if this can be organised without impacting on visibility) and changing the time of events to evening to avoid peak UVR times; extending the availability of other types of sun protection, Eg: sunscreen; and introducing related policies and signage.

In Australia, as UVR levels and ambient temperatures continue to rise in the future, the associated risk of skin cancer will increase. Incidence rates of cutaneous melanoma have been increasing during the last 30-40 years; the highest rates have been documented in Australia and New Zealand (27.9/100,000 among males and 25.0 among females) and in North America (10.9/100,000 among males and 7.7 among females) [36]. There is also a skin cancer epidemic in the United States [37]. 
We agree with Lazovich that it is time to get serious about better protecting ourselves and our children from the risk of future skin cancer [37]. Further targeted public sun safety campaigns are warranted.

\section{Study limitations and strengths}

This data is from a cross-sectional observation at one motoring event, taken by one sole observer at one point in time. The study would have been stronger if a number of observers had been used and their reliability through inter-rater comparison had been confirmed. It would also have been stronger if a number of different events had been observed. Lower-body garments and sunglasses were not recorded. This observational study may be limited by the fact that there is no measure of the use of sun screen and what kind of sun-screen. Demographic data was not collected, as this was an observational study. There may be differences in sun protective behaviours between people who are walking, sitting and standing. This study only observed walking spectators. Once reaching their seat/position, they may have put on a hat they were carrying or behaved differently in some other way.

Notwithstanding these limitations, this study is the first to document simultaneous observations of hat wearing and sleeve-length at an outdoor sporting activity in tropical Australia.

In this study, only $27.1 \%$ of adults and $45.0 \%$ of children wore hats providing adequate protection from ultraviolet radiation (UVR), and $10.7 \%$ of adults and $9.8 \%$ of children wore sleeves which protected most of the upper limbs. Despite a widespread Sun Smart campaign in Australia over the past three decades, observed sun protection behaviours at this event were not consistent with Cancer Council Australia recommendations for personal sun protection.

\section{Conflict Of Interest Statement}

No financial disclosures were reported by the authors of this paper.

\section{Author's Contribution}

JN drafted and finalised the manuscript and analysed the data. SLH conceived the project, conducted the observations, revised the data analysis and approved the final manuscript.

\section{Acknowledgments}

Queensland Health provided some of the salary support that allowed us to conduct this research.

\section{References}

1. Department of Health and Aging (2013) Key statistics of incidence and mortality of skin cancer in Australia.

2. Fransen M, Karahalios A, Sharma N, English DR, Giles GG, et al. (2012) Non-melanoma skin cancer in Australia. Med J Aust 197: 565-568.

3. Australian Bureau of Statistics (2012) Causes of death 2011 Commonwealth of Australia: Canberra, Australia

4. Buettner PG, Raasch BA (1998) Incidence rates of skin cancer in Townsville, Australia. Int J Cancer 78: 587-593.

5. Cancer Council Queensland Cancer incidence, mortality, survival and prevalence.
6. Sinclair C, Dobbinson S, Montague M (2009) Can a skin cancer control programme make a difference? a profile of the Sun Smart programme in Victoria. Radiat Prot Dosimetry 91: 301-302.

7. Glanz K, Chang L, Song V, Silverio R, Muneoka L (1998) Skin cancer prevention for children, parents, and caregivers: a field test of Hawaii's SunSmart program. J Am Acad Dermatol 38: 413-417.

8. The Cancer Association of South Africa 2010. Be SunSmart: A guide for schools. In: CANSA (ed.). Bedfordview, South Africa.

9. Trapp D, Harrison SL, Nowak M, Buettner PG (2010) An evaluation of the sun protective practices of Townsville primary school students. Annals of the ACTM 11:50.

10. Makin JK, Warne CD, Dobbinson SJ, Wakefield MA, Hill DJ (2013) Population and age-group trends in weekend sun protection and sunburn over two decades of the SunSmart programme in Melbourne, Australia. Br J Dermatol 168: 154-161.

11. Armstrong BK, Kricker A (1993) How much melanoma is caused by sun exposure? Melanoma Res 3: 395-401.

12. Gilaberte Y, Carrascosa JM (2013) Sun Protection in Children: Realities and Challenges. Actas Dermosifiliogr 105: 253-262

13. Kelly JW, Rivers JK, MacLennan R, Harrison S, Lewis AE, et al. (1994) Sunlight: a major factor associated with the development of melanocytic nevi in Australian schoolchildren. J Am Acad Dermatol 30: 40-48.

14. Harrison SL, MacKie RM, MacLennan R (2000) Development of melanocytic nevi in the first three years of life. J Natl Cancer Inst 92: 1436-1438.

15. Dobbinson SJ, Jamsen K, Dixon HG, Spittal MJ, Lagerlund M, et al. (2014) Assessing population-wide behaviour change: concordance of 10year trends in self-reported and observed sun protection. Int J Public Health 59: 157-166.

16. Parr CL, Hjartåker A, Laake P, Lund E, Veierød MB (2009) Recall bias in melanoma risk factors and measurement error effects: a nested casecontrol study within the Norwegian Women and Cancer Study. Am J Epidemiol 169: 257-266.

17. Johnston J. Chance to air V8 race gripes. Townsville Bulletin. News Limited: Townsville.

18. Turner D, Harrison SL, Buettner P, Nowak M (2014) Does being a "SunSmart School" influence hat-wearing compliance? An ecological study of hat-wearing rates at Australian primary schools in a region of high sun exposure. Prev Med 60: 107-114.

19. Weather history for Townsville, Queensland.

20. Staples MP, Elwood M, Burton RC, Williams JL, Marks R, et al. (2006) Non-melanoma skin cancer in Australia: the 2002 national survey and trends since 1985. Med J Aust 184: 6-10.

21. Jinna S, Adams BB (2013) Ultraviolet radiation and the athlete: risk, sun safety, and barriers to implementation of protective strategies. Sports Med 43: 531-537.

22. Saraiya M, Glanz K, Briss PA, Nichols P, White C, et al. (2004) Interventions to prevent skin cancer by reducing exposure to ultraviolet radiation: a systematic review. Am J Prev Med 27: 422-466.

23. Gies P, Javorniczky J, Roy C, Henderson S (2006) Measurements of the UVR protection provided by hats used at school. Photochem Photobiol 82: 750-754

24. Diffey BL, Cheeseman J (1992) Sun protection with hats. Br J Dermatol 127: $10-12$.

25. Downs N, Parisi A (2008) Patterns in the received facial UV exposure of school children measured at a subtropical latitude. Photochem Photobiol 84: 90-100.

26. Linos E, Keiser E, Fu T, Colditz G, Chen S, et al. (2011) Hat, shade, long sleeves, or sunscreen? Rethinking US sun protection messages based on their relative effectiveness. Cancer Causes Control 22: 1067-1071.

27. Harrison S, Buettner PG, MacLennan R, Woosnam J, Hutton L, et al. (2010) Sun-safe clothing helps to prevent the development of pigmented moles - Results of a randomised control trial in young Australian children. Annals of the ACTM : 51 . 
Citation: Nikles J and Harrison SL (2014) An Observational Study of Sun-Protective Behaviour at an Outdoor Spectator Sporting Event in a Region of High Sun Exposure . J Carcinog Mutagen S4: 003. doi:10.4172/2157-2518.S4-003

Page 6 of 6

28. Ghazi S, Couteau C, Coiffard LJ (2010) What level of protection can be obtained using sun protective clothing? Determining effectiveness using an in vitro method. Int J Pharm 397: 144-146.

29. Dixon HG, Lagerlund M, Spittal MJ, Hill DJ, Dobbinson SJ, et al. (2008) Use of sun-protective clothing at outdoor leisure settings from 1992 to 2002: serial cross-sectional observation survey. Cancer Epidemiol Biomarkers Prev 17: 428-434.

30. Lagerlund M, Dixon HG, Simpson JA, Spittal M, Taylor HR, et al. (2006) Observed use of sunglasses in public outdoor settings around Melbourne, Australia: 1993 to 2002. Prev Med 42: 291-296.

31. Anti-Cancer Council of Victoria. Australian Open fans slap on hats as tennis hots up.

32. Rigel AS, Lebwohl MG (2006) Hat-wearing patterns in persons attending baseball games. J Am Acad Dermatol 54: 918-919.

33. Queensland Health (2012) Self-reported health status 2012: preventive health indicators, Queensland. Queensland Health: Brisbane.
34. Dadlani C, Orlow SJ (2008) Planning for a brighter future: a review of sun protection and barriers to behavioral change in children and adolescents. Dermatol Online J 14: 1 .

35. Wickenheiser M, Baker MK, Gaber R, Blatt H, Robinson JK (2013)Sun protection preferences and behaviors among young adult males during maximum ultraviolet radiation exposure activities. Int J Environ Res Public Health: 3203-3216.

36. Stracci F, Minelli L, D'Alò D, Fusco-Moffa I, Falsettini E, et al. (2005) Incidence, mortality and survival trends of cutaneous melanoma in Umbria, Italy. 1978-82 and 1994-98. Tumori 91: 6-8.

37. Lazovich D, Choi K, Vogel RI (2012) Time to get serious about skin cancer prevention. Cancer Epidemiol Biomarkers Prev 21: 1893-1901. 